\title{
ANALYSIS OF HIGHER EDUCATION MARKETING MIX IN IMPROVING THE IMAGE OF VOCATIONAL COLLEGES
}

\author{
Iwan Mulyawan ${ }^{1, \nabla)}$, Wahyu Rafdinal ${ }^{2)}$ \\ Administrasi Niaga, Politeknik Negeri Bandung, Bandung, 40012 \\ E-mail: ${ }^{1}$ imulyawan@polban.ac.id
}

\begin{abstract}
This study aims to analyze the effect of the marketing mix of higher education on the image of vocational colleges. The sampling technique is purposive sampling with 200 respondents. The analysis technique used is SEM PLS. The results showed that the marketing mix can affect the image of vocational colleges. People consisting of staff and lecturers gave the biggest contribution in improving the image of vocational colleges. The process of service and physical evidence also contributes greatly to the image of vocational colleges.
\end{abstract}

Keywords: Marketing mix, Image, Vocational Higher Education

\begin{abstract}
ABSTRAK
Penelitian ini bertujuan untuk menganalisis pengaruh bauran pemasaran perguruan tinggi terhadap citra perguruan tinggi vokasi. Teknik pengambilan sampel yaitu purposive sampling dengan jumlah responden sebanyak 200 responden. Teknik analisis yang digunakan yaitu SEM PLS. Hasil penelitian menunjukan bahwa bauran pemasaran dapat mempengaruhi citra perguruan tinggi. Pople yang terdiri dari staff dan dosen memberikan kontribusi terbesar dalam meningkatkan citra perguruan tinggi vokasi. prosess penyampaian jasa dan bukti fisik perguruan tinggi juga memberikan kontribusi yang besar terhadap citra perguruan tinggi vokasi.
\end{abstract}

Kata Kunci: Bauran Pemasaran, Citra, Pendidikan Tinggi Vokasi

\section{PENDAHULUAN}

Persaingan antara perguruan tinggi memaksa untuk terus menerus meningkatkan pendekatan strategi dalam meningkatkan kualitas input mahasiswa baru. Perguruan tinggi harus melakukan perbaikan dari berbagai sisi seperti pelayanan yang diberikan, keringanan biaya pendidikan, promosi untuk menyampaikan keunggulannya, distribusi pengetahuan, peningkatan kualitas dosen dan staf, perbaiakan proses pengajaran, dan lingkungan kampus yang kondusif. Penting bagi Perguruan Tinggi untuk menganalisis faktor yang mempengaruhi citra perguruan tinggi untuk dapat bersaing dan menentukan strategi pemasaran yang tepat sehingga mendapatkan input mahasiswa yang berkualitas.
Citra perguruan tinggi mewakili serangkaian sikap, gagasan, dan kesan yang dimiliki calon mahasiswa terkait dengan perguruan tinggi itu (Lukic, 2017). Citra adalah jumlah dari kepercayaan, ide, dan kesan seseorang terhadap suatu tempat (Jani 2014) dan organisasi (Wu 2014). Citra adalah konsep penting dalam riset perilaku konsumen karena memengaruhi individu, persepsi subjektif, nilai konsumen, kepuasan, dan niat perilaku membeli (Jin 2015). Citra Perguruan Tinggi vokasi juga dapat dilihat dari dilihat dari Precence dan Visibility pada peringkat Webometric berikut: 
Tabel 1 Peringkat Perguruan Tinggi Vokasi Berdasarkan Webometric

\begin{tabular}{lllll}
\hline $\begin{array}{l}\text { Ranking } \\
\text { Indonesia }\end{array}$ & Institusi & $\begin{array}{l}\text { Precense } \\
\text { Rank }\end{array}$ & $\begin{array}{l}\text { Impact } \\
\text { Rank }\end{array}$ & $\begin{array}{l}\text { Openness } \\
\text { rank }\end{array}$ \\
\hline 107 & Politeknik Negeri Bandung & 3620 & 6560 & 4388 \\
556 & Polteknik Manufaktur Bandung & 513 & 21520 & 9658 \\
928 & Politeknik Pajajaran & 20296 & 22211 & 11401 \\
503 & Politeknik POS Indonesia & 9759 & 15311 & 11401 \\
949 & Politeknik LP3I Bandung & 15424 & 25340 & 10053 \\
687 & Politeknik TEDC Bandung & 10175 & 23220 & 8855 \\
1139 & Politeknik Praktisi Bandung & 23196 & 24142 & 11401 \\
582 & Politeknik Piksi Ganesha & 5112 & 22483 & 8049 \\
1775 & Politeknik al-Islam bandung & 12436 & 27690 & 11401 \\
\hline
\end{tabular}

Sumber: Webometrics, 2019

Peningkatan citra Perguruan Tinggi vokasi dapat dilakukan dengan menganalisis faktor yang mempengaruhinya yaitu strategi bauran pemasaran yang diterapkan oleh Perguruan Tinggi vokasi seperti pelayanan, biaya pendidikan, promosi perguruan tinggi, lokasi, kualitas dosen dan staf, proses, dan lingkungan kampus yang kondusif. Citra perguruan tinggi berkaitan dengan variabel bauran pemasaran (marketing mix). Produk adalah layanan fisik atau jasa kepada konsumen yang ingin membayar (Išoraite 2016). Ketika mempertimbangkan bauran pemasaran di perguruan tinggi adalah kurikulum dan layanan yang akan ditawarkan, mitra dan publik lainnya, semua program dan layanan yang disediakan oleh perguruan tinggi (Gajić 2012). Kemudian, harga adalah salah satu faktor yang mempengaruhi konsumen, karena itu membantunya memahami nilai produk (Išoraite 2016). Calon mahasiswa dan keluarga mereka dapat tertarik dengan harga dan nilai yang diterima dalam memilih perguruan tinggi (Gajić 2012). Biaya yang dikeluarkan pelanggan merupakan salah satu elemen bauran pemasaran yang dapat mempengaruhi keputusan pembelian. Penelitian Owusu (2013) dan Salamin (2016) menunjukan harga berpengaruh terhadap keputusan pembelian. Harga membutuhkan perhatian khusus kerena berhubungan pada pendapatan konsumen (Hustić, 2015).
Elemen bauran pemasaran yaitu promosi, pengguna layanan perguruan tinggi perlu diberi tahu tentang tujuan, kegiatan, dan penawaran jasanya (Gajić 2012). Elemen bauran pemasaran lainnya adalah tempat yang juga disebut distribusi didefinisikan sebagai proses dan metode yang digunakan agar layanan dapat menjangkau pelanggan (Išoraitè 2016). Sebagian besar lembaga telah memiliki bangunan di satu atau lebih tempat. Ketika sebuah institusi pendidikan mulai berpikir untuk meningkatkan pelayanannya, hal itu diupayakan untuk diwujudkan dalam fasilitas yang ada (Gajić 2012). Cara pengetahuan didistribusikan sangat penting baik secara langsung atau online (Lukic, 2017).

People sebagai instrumen kunci dalam proses pendidikan yang terdiri dari tenaga pengajar, staf, siswa dan mitra lainnya di lingkungan perguruan tinggi (Gajić 2012). People terkait dengan aksesibilitas pengajar, kesopanan staf, metode pengajaran, keahlian pengajar dan layanan pendidikan (Lukic, 2017). Mahasiswa menerima layanan ini dari staf pengajar yang ahli dan dapat diakses yang memanfaatkan berbagai teknik pengajaran. Elemen bauran pemasaran lainnya adalah proses yang terlibat dalam menciptakan layanan pendidikan (Gajić 2012). Keahlian tenaga pengajar dalam persiapan sistem, metode, dan cara pengajaran maka hasilnya akan produktif dan siswa akan belajar dengan berkualitas. Pada elemen bauran 
pemasaran bukti fisik, lingkungan layanan memberikan gambaran eksternal tentang jenis layanan apa yang dapat diharapkan (Gajić 2012).

Manajemen bauran pemasaran yang efektif memungkinkan pemasar untuk membuat kombinasi elemen yang memungkinkan pengelolaan anggaran dengan bijak untuk mencapai tujuan yang diinginkan (Išoraitè 2016). Untuk itu penting bagi Perguruan tinggi vokasi dalam menganalisis faktor yang dapat meningkatkan citra Perguruan Tinggi dan kemudian menerapkan strategi bauran pemasaran perguruan tinggi yang tepat sehingga dapat meningkatkan citra Perguruan tinggi vokasi dan meningkatkan Peringkat Perguruan tinggi vokasi di Bandung ke depannya.

\section{METODE PENELITIAN}

Penelitian ini termasuk penelitian kuantitatif yang berbentuk deskriptif. Penelitian deskriptif mencoba menggambarkan, menjelaskan dan menafsirkan suatu fenomena yang ada atau yang terjadi pada suatu objek dan kemudian menganalisis hubungan antara variabel melalui suatu pengujuian hipotesis. Instrumen yang akan digunakan dalam penelitian ini adalah kuesioner. Instrumen bauran pemasaran diadopsi dari beberapa penelitian mengenai bauran pemasaran pada perguruan tinggi yang dikembangkan oleh Lukic (2017) dan Gajić (2012). Citra perguruan tinggi diukur dengan tiga indikator yang dikembangkan Brown (2009). Kemudian intrumen untuk mengukur keputusan pemilihan perguruan tinggi didasarkan pada penelitian Lien (2015) dan Agag (2016). Teknik pengambilan sampel yaitu purposive sampling, yang merupak teknik pengambilan sampel dengan mempertimbangkan beberapa kriteria responden seperti: 1) Responden adalah pelajar kelas XII, 2) Berdomisili di Jawa Barat, 3) Memiliki keinginan untuk melanjutkan ke perguruan tinggi. Jumlah sampel dalam penelitian ini yaitu sebanyak 200 responden yang terdiri dari siwa SMA ataupun SMK. Teknik analisis yang digunakan dalam penelitian ini adalah analisis Structural Equation Model (SEM) berbasis Partial Least Square (PLS).

\section{HASIL DAN PEMBAHASAN}

Teknik analisis yang digunakan dalam penelitian ini yaitu dengan SEM PLS. Metode partial least square (PLS) dapat digunakan untuk menganalisis data dalam model persamaan struktural, karena teknik ini lebih tepat untuk penelitian eksplorasi dan studi dengan ukuran sampel kecil. Terdapat dua tahap analisis yaitu pertama, dengan menilai keandalan dan validitas model pengukuran (outer model), dan kedua, dengan menilai model struktural (inner model).

\section{a. Outer Model}

Untuk mengevaluasi model pengukuran, perlu memperkirakan ketelitian instrumen pengukuran dalam memberikan angka bebas dari random errors dan sejauh mana angka-angka yang diperoleh dengan skala mencerminkan perbedaan yang sebenarnya antara objek. dan fitur yang diukur (covergent validity dan discriminan validity). Average variance extracted (AVE) digunakan untuk mengevaluasi covergent validity (Fornell \& Larcker, 1981). Nilai AVE yang diperoleh melebihi minimum yang disarankan 0,5 untuk semua construct (Table 2). 
Tabel 2 Contruct Validity dan Reliability

\begin{tabular}{llcccc}
\hline & Item & Loading Faktor & A & CR & AVE \\
\hline Marketing Mix & X1 & 0.663 & 0,870 & 0,899 & 0,562 \\
& X2 & 0.742 & & & \\
X3 & 0.703 & & & \\
& X5 & 0.723 & & & \\
X6 & 0.861 & & & \\
& X7 & 0.739 & & & \\
& IG1 & 0.622 & 0,853 & 0,888 & \\
& IG2 & 0.714 & & & \\
& IG3 & 0.741 & & & \\
& IG4 & 0.817 & & & \\
& IG5 & 0.805 & & & \\
& IG6 & 0.744 & & & \\
& IG7 & 0.649 & & & \\
& IG8 & 0.622 & & & \\
\hline
\end{tabular}

Berdasarkan Tabel 2, dapat dinyatakan bahwa semua skor pemuatan tidak di bawah 0,5, sehingga tidak ada indikator yang harus dihapus dari model penelitian, sehingga langkah selanjutnya adalah melakukan uji validasi diskriminan. Dalam mengukur validitas diskriminan melalui PLS dapat menggunakan cross-loading dari indikator berdasarkan pendapat Hair (2014), mensyaratkan bahwa pemuatan masing-masing indikator pada konstruknya lebih tinggi daripada beban silang pada konstruksi lain (Tabel 3) .

Tabel 3. Discriminant Validity dan Cross Loading

\begin{tabular}{lcc}
\hline Indikator & Marketing_Mix & Image \\
\hline X1 & $\mathbf{0 . 6 6 3}$ & 0.361 \\
X2 & $\mathbf{0 . 7 4 2}$ & 0.314 \\
X3 & $\mathbf{0 . 7 0 3}$ & 0.329 \\
X4 & $\mathbf{0 . 7 2 3}$ & 0.386 \\
X5 & $\mathbf{0 . 8 6 1}$ & 0.442 \\
X6 & $\mathbf{0 . 7 3 9}$ & 0.544 \\
X7 & $\mathbf{0 . 8 0 0}$ & 0.472 \\
X8.2 & 0.389 & $\mathbf{0 . 6 2 2}$ \\
X8.3 & 0.370 & $\mathbf{0 . 7 1 4}$ \\
X8.4 & 0.472 & $\mathbf{0 . 7 4 1}$ \\
X8.5 & 0.478 & $\mathbf{0 . 8 1 7}$ \\
X8.6 & 0.434 & $\mathbf{0 . 8 0 5}$ \\
X8.7 & 0.380 & $\mathbf{0 . 7 4 4}$ \\
X8.8 & 0.297 & $\mathbf{0 . 6 4 9}$ \\
\hline
\end{tabular}

Catatan. Cetak tebal adalah loading dari indicator pada konstruk

Kemudian dengan menggunakan kriteria Fornell-Larcker, yang menganalisis apakah korelasi antara dimensi lebih rendah dari akar kuadrat dari AVE (Fornell 1981)

(Tabel 4). Serta dengan menggunakan heterotrait-monotrait (HTMT) rasio 
korelasi antara dua konstruksi harus di bawah 0,9 (Henseler, Ringle, and Sarstedt 2015) (Tabel 4). Semua nilai ditentukan di bawah batas standar yang ditentukan. Hasil pengukuran discriminant validity dengan menggunakan cross loading, FornellLarcker Criterion dan HeterotraitMonotrait Ratio (HTMT) menunjukan bahwa setiap indikator dan konstruk berada pada kriteria valid.

Table 4 Discriminant Validity: Fornell-Larcker Criterion And Heterotrait-Monotrait Ratio (HTMT)

\begin{tabular}{lcc}
\hline & Image & Marketing Mix \\
\hline Image & 0.731 & 0.621 \\
Marketing Mix & 0.560 & 0.750 \\
\hline
\end{tabular}

Catatan. Kriteria Fornell-Larcker (di bawah diagonal utama) dan Rasio Heterotrait-Monotrait (HTMT) (di atas diagonal utama).

\section{b. Inner Model}

Pengujian model struktural dengan memasukkan semua pernyataan yang dinyatakan lulus uji validitas dan reliabilitas. Evaluasi model struktural memenuhi semua persyaratan umum. Pertama, Nilai R2 menunjukkan berapa banyak varian konstruk dapat dijelaskan oleh model. Nilai R2 pada variabel citra sebesar 0,310. Uji model struktural menunjukkan hubungan variabel laten dengan variabel laten lainnya. Hasil menunjukkan bahwa model yang diusulkan dapat diterima. Berdasarkan hasil pengujian hipotesis menunjukkan bahwa bauran pemasaran secara langsung berpengaruh signifikan terhadap citra perguruan tinggi vokasi dengan koefisien jalur sebesar 0,560 . Hal ini berarti bahwa bauran pemasaran perguruan tinggi dapat mempengaruhi citra perguruan tinggi vokasi.

Tabel 5. Hasil Pengujian Inner Model

\begin{tabular}{|c|c|c|c|c|}
\hline & $\begin{array}{l}\text { Original Sample } \\
\text { (O) }\end{array}$ & $\begin{array}{l}\text { Sample Mean } \\
\text { (M) }\end{array}$ & $\begin{array}{l}\text { Standard Deviation } \\
\text { (STDEV) }\end{array}$ & P Values \\
\hline $\begin{array}{l}\text { Marketing_Mix } \\
\text { terhadap Citra } \\
\text { Perguruan Tinggi }\end{array}$ & 0.560 & 0.566 & 0.044 & 0.000 \\
\hline
\end{tabular}

Hasil analisis menunjukan bahwa bauran pemasaran perguruan tinggi berpengaruh signifikan terhadap citra perguruan tinggi. Semakin baik bauran pemasaran maka dapat meningkatkan citra perguruan tinggi vokasi. Hasil ini menggambarkan bahwa bauran pemassaran perguruan tinggi yang terdiri dari jasa layanan, biaya pendidikan, lokasi, promosi, staf dan dosen, proses penyampaian jasa, dan bukti fisik infrastruktur perguruan tinggi dapat mempengaruhi citra perguruan tinggi vokasi. Hal ini penting bagi perguruan tinggi vokasi untuk mempertimbangkan dan mengelola faktor tersbut untuk menciptakan citra perguruan tinggi yang lebih baik. Hasil penelitian (Kai Li 2009) menunjukan bahwa strategi pemasaran (product, people, price, place, and promotion) berpengaruh terhadap citra institusi. Pada perguruan tinggi vokasi, peran staf dan tenaga pengarjar berperan penting dalam penyampaian jasa pendidikan. Peran sumber daya manusia dapat mempengaruhi citra institusi (Dominguez 2011). Beberapa elemen bauran pemasaran yaitu promosi dan channel berpengaruh terhadap citra institusi (Kim, 2011). Dalam meningkatkan citra, setiap organisasi perlu mempertimbangkan preferensi pasar (Yeo 2011).

Citra perguruan tinggi mewakili sikap, gagasan, dan kesan yang dimiliki calon mahasiswa terkait dengan perguruan 
tinggi itu (Lukic, 2017). Citra secara keselurahan terbagi menjadi citra kognitif dan citra affectif (Molinillo 2018). Citra adalah konsep penting dalam riset perilaku konsumen karena memengaruhi individu, persepsi subjektif, nilai konsumen, kepuasan, dan niat perilaku membeli (Jin 2015). Citra adalah jumlah dari kepercayaan, ide, dan kesan seseorang terhadap suatu tempat (Jani 2014) dan organisasi (Wu 2014). Citra berpengaruh positif pada niat perilaku membeli, menyiratkan bahwa pelanggan membentuk kesan positif terhadap citra organisasi (Wu 2014). Kesadaran dan citra diakui sebagai tujuan utama dari implementasi komunikasi pemasaran terpadu (IMC) (Foroudi 2017). Citra perguruan tinggi bepengaruh besar pada pilihan perguruan tinggi. Citra menjadi indikator utama keunikan pendidikan tinggi dengan munculnya branding, seperti identitas merek dan citra untuk mengembangkan identitas perguruan tinggi, meningkatkan citra, dan meningkatkan reputasi (Brown, 2016). Persaingan antar perguruan tinggi ikut meningkatkan kebutuhan perguruan tinggi untuk memahami, mengelola, dan memanfaatkan posisi nama perguruan tinggi yang kuat (Rauschnabel 2016). Citra perguruan tinggi yang ditentukan oleh staf akademiknya, berbeda dari citra perguruan tinggi ditentukan oleh lulusan yang dihasilkan (Foroudi 2017).

\section{KESIMPULAN}

Hasil penelitian ini memiliki implikasi praktis yang relevan untuk praktisi praktisi perguruan tinggi vokasi dalam merancang rencana strategis untuk meningkatkan citra perguruan tinggi vokassi. Pertama, Praktisi pendidikan tinggi kejuruan perlu membangun citra perguruan tinggi dengan menerapkan strategi bauran pemasaran perguruan tinggi yang tepat. Kedua, perlu perlu memaksimal pengalaman siswa saat ini dalam rangka meningkatkan citra perguruan tinggi vokasi. Ketiga, penelitian ini menegaskan bahwa bauran pemasaran perguruan tinggi dapat dipenagruhi citra perguruan tinggi vokasi. Akibatnya, praktisi perguruan tinggi vokasi perlu mengambangkan strategi bauran pemasaran perguruan tinggi yang sesuai dengan layanan pendidikan yang baik, biaya pendidikan yang sesuai, tersedianya pembelajaran online, pembelajaran sacara langsung dengan metode yang sesuai, menyesuaikan jumlah biaya pendidikan, proses penyampaian layanan yang staf dan tenaga pengaajar yang profesional, dan bukti fisik perguruan tinggi berupa infrastruktur yang baik. Jika hal ini dapat disesuaikan dan diterapkan oleh perguruan tinggi maka dapat meningkatkan citra perguruan tinggi vokasi. Kelima, persaingan antar perguruan tinggi dalam mendapatkan mahasiswa perlu menjadi peritimbangan pihak perguruan tinggi yang kemudian dapat digunakan dalam perencanaan strategi dan rencana pemasaran yang tepat.

Strategi bauran pemasaran perguruan tinggi masih relevan dalam menciptakan citra perguruan tinggi vokasi. Perguruan tinggi vokasi mempertimbangkan faktor seperti pelayanan pendidikan yang baik, biaya pendidikan, lokasi perguruan tinggi online dan offline, promosi dan beasiswa pendidikan, staf dan tenaga pengajar, proses penyampaian jasa, dan infrastruktur perguruan tinggi sehingga dapat menghasilkan citra perguruan tinggi yang baik sehingga mampu bersaing dengan perguruan tinggi lainnya.

\section{DAFTAR PUSTAKA}

[1] Agag, Gomaa and Ahmed A. ElMasry. 2016. "Understanding Consumer Intention to Participate in Online Travel Community and Effects on Consumer Intention to 
Purchase Travel Online and WOM: An Integration of Innovation Diffusion Theory and TAM With Trust." Computers in Human Behavior 60:97-111.

[2] Al-Salamin, Hussain and Eman AlHassan. 2016. "The Impact of Pricing on Consumer

[3] Buying Behavior in Saudi Arabia: Al-Hassa Case Study." European Journal of Business and Management 8(12):62-73.

[4] Brown, Robert M. and Timothy William Mazzarol. 2009. "The Importance of

[5] Institutional Image to Student Satisfaction and Loyalty Within Higher Education." Higher Education 58(1):81-95.

[6] Dominguez, Alvarez. 2011. "The Impact of Human Resource Disclosure on Corporate Image." Journal of Human Resource Costing \& Accounting 15(4):279-98.

[7] Fornell, Claes. 1981. "Evaluating Structural Equation Models with Unobservable Variables and Measurement Error." Journal of Marketing Research 18(1):39-50.

[8] Foroudi, Pantea. 2017. "IMC Antecedents and The Consequences of Planned Brand Identity in Higher Education." European Journal of Marketing 51(3):528-50.

[9] Gajić, Jelena. 2012. "Importance of Marketing Mix in Higher Education Institution.” Singidunum Journal 9(1):29-41.

[10]Hair, J. F. 2014. Multivariate Data Analysis. 7th ed. New jersey: Pearson Education.Inc.

[11]Hemsley-Brown, Jane. 2016. "Exploring Brand Identity, Meaning, Image, and Reputation (BIMIR) in Higher Education: A Special Section." Journal of Business Research 69(8):3019-22.

[12] Henseler, Jörg, Christian M. Ringle, and Marko Sarstedt. 2015. “A New Criterion for Assessing
Discriminant Validity in VarianceBased Structural Equation Modeling.” Journal of the Academy of Marketing Science 43(1):115-35.

[13] Hustić, Ivana and Iva Gregurec. 2015. "The Influence of Price on Customer 's Purchase Decision.” Information and Intellegent Systems (9):27-32.

[14] Išoraitè, Margarita. 2016. "Marketing Mix Theoretical Aspects." International Journal of Research-Granthaalayah 4(6):2537.

[15] Jani, Dev. 2014. "Personality, Satisfaction, Image, Ambience, and Loyalty: Testing Their Relationships in The Hotel Industry." International Journal of Hospitality Management 37:11-20.

[16] Jin, Naehyun Paul. 2015. "The Effect of Experience Quality on Perceived Value, Satisfaction, Image and Behavioral Intention Of Water Park Patrons: New Versus Repeat Visitors.” International Journal of Tourism Research 17(1):82-95.

[17] Kai Li, Chung. 2009. "Marketing Tactics and Parents ' Loyalty: The Mediating Role of School Image." Journal of Educational Administration 47(4):477-89.

[18] Kim, Ji Hern and Yong J. Hyun. 2011. "A Model to Investigate the Influence of Marketing-Mix Efforts and Corporate Image on Brand Equity in the IT Software Sector." Industrial Marketing Management 40:424-38.

[19]Lien, Che Hui, Miin Jye Wen, Li Ching Huang, and Kuo Lung Wu. 2015. "Online Hotel Booking: The Effects of Brand Image, Price, Trust and Value on Purchase Intentions.” Asia Pacific Management Review 20(4):210-18. 
[20] Molinillo, Sebastian. 2018. "DMO Online Platforms: Image and Intention to Visit.” Tourism Management 65:116-30.

[21] Owusu, Alfred. 2013. "Influences of Price And Quality On Consumer Purchase Of Mobile Phone In The Kumasi Metropolis In Ghana A Comparative Study.” European Journal of Business and Management 5(1):179-98.

[22] Rauschnabel, Philipp A. 2016. "Brand Management in Higher Education: The University Brand Personality Scale." Journal of Business Research 69(8):3077-86.

[23] Rodic-Lukic, Vesna and Nemanja Lukic. 2017. "Application of Marketing Mix Concept in Student Recruitment Strategies: Evidence From University of Novi Sad, Serbia." Megatrend Review 13(3):183-202.

[24] Wu, Hung Che. 2014. "The Effects of Customer Satisfaction, Perceived Value, Corporate Image and Service Quality on Behavioral Intentions in Gaming Establishments.” Asia Pacific Journal of Marketing and Logistics 26(4):540-65.

[25] Yeo, Roland K. 2011. "Corporate Image and Reputation of Large Mainland Chinese Enterprises.” Journal of Marketing Communications 17(3):195-211. 